\title{
E-MECHATRONICS: DIGITAL CONTENT IN TRANSFORMATION OF TEACHING AND LEARNING
}

This article deals with mechatronics as a one of the leading and fast growing world industrial and economic sectors, for which in educational niche it is critical to provide enriched digital contents through a homogenous training tool. Mechatronics is from now based on historical know-how but truly needs to evolve through enhanced collaboration with various industries: home and office products, transport, automotive, space, etc. Providing the eContent of mechatronics as a common training tool that will help these multidisciplinary collaborations and strength exchanges within these scientific and technological areas eMECHATRONICS will position itself at the junction of mechanics, electronics and software engineering. The article is based on more than 15 years experiences at University of Zilina in mechatronics, and linguistic contribution, as well as in the analysis in the existing digital content, knowledge and know-how available at the educational, professional and public level in these different scientific and technological domains. Such eContent will serve, as described in this article, to propose and enhance web-based training services, providing mechatronics-related knowledge according to the individual level, language competency and needs of its users, may they be students, professionals or individuals.

\section{Introduction to eMECHATRONICS}

eMECHATRONICS represents a significant role of an amount of training documents, case studies and other relevant materials and tools providing mechatronics added value knowledge [1]. Nevertheless such support truly needs to be enriched, mostly to enable interactions between the mechatronics various scientific and technological areas to be covered. The eMECHATRONICS web-based training solution will then propose enriched digital content according to its user's origin, level of scientific and technological expertise and knowledge as well as of its previous use of the eMECHATRONICS service. eMECHATRONICS will also ensure multilingual and cultural adaptation. eMECHATRONICS work to be carried out will include:

- Search, define and classify existing documents.

- Analyse the user needs and manners of solving problems in order to propose solving problem typologies to be implemented in the user interface,

- Define the user needs in view of constituting the ontologies to improve by means of semantic technology the annotation, enrichment and organisation of existing digital content.

- Construct the tools to search and enrich the existing educating digital documents, the training tool and user-friendly knowledge database interface.

- Constitute the database, implement it within the training tool and test and adapt it after validation by a first end-user group.

- Define the various levels of information and their access (private, common or public information), the intellectual rights and quality survey of the product.

- Implement the tool for profiling, filtering and managing the digital content taking also into account the economic return for each content producer.
- Adapt and implement the tool and content of the learning service to user with various profiles and languages.

- Widely deploy and constantly update the eMECHATRONICS service.

- Implement wide commercial eMECHATRONICS training service.

\section{The eContent characteristics}

Digital content, in modern eContent, is oriented to university and market programme which aims to support the production, use and distribution of digital content and to promote linguistic and cultural diversity on the global networks. eMECHATRONICS will implement continuous activities devoted to the control and assessment of the progress and results in mechatronics [2], [3], [4]. Indicators and metrics should be defined to achieve such evaluation, among them we can note:

- number and quality of reachable digital documents contained in the knowledge database,

- number of entries of thesaurus, meta-data specifications and domain ontologies and content of multilingual glossary,

- number and quality of training elements and completion and quality of problem solving tools,

- quantity and quality survey with statistics about access count to the database, to the training and decision-helping tools with duration of use and training time.

Digital content and networked applications will support transformative changes in the approach to teaching and learning of mechatronics. In order for these changes to lead to increased educational opportunities for all students, digital content and net-

\footnotetext{
* Pavel Pavlásek

Faculty of Electrical Engineering, University of Zilina, E-mail: Pavel.Pavlasek@fel.utc.sk
} 
worked applications must be independently judged to be of high quality in the terms of science and didactical effectiveness, welldocumented, comprehensive and available for all grades heterogeneous groups and have the power to insipre or motivate students. In addition, eContent must be easy to find and access, easy for students and teachers to use. Todays CA.instruments offer tremendous opportunities for creation of powerful eContent by helping students to comprehend difficult to understand mechatronical concepts, helping students to engage in learning, providing students with access to information resources and remote technology. eContent makes better contribution to the students individual needs, and improve the accountability and effeciency of university administration. High speed connection to the Internet had the opportunity to expand and extend eContent previously established learning program. At the time eContent established itself as a leader in mechatronics training in CA.technologies (CAD software), remote access to online hardware units (Rapid Prototyping machines), development and test software (Virtual Labs - Matlab, Simulink, LabView, etc.) and video conferencing as a regularly scheduled master classes, one-to-one teaching sessions, educational and community programs, and professional development programs [5], [6], [7]. The manufacturing lines present mechatronic systems in industrial environment. Elements critical to eMECHATRONICS education - visual imagery, movement, virtual modelling, parameters simulation, and the like are almost completely compromised with the real environment, and although many innovation in technology, the limits of the support are in eContent of mechatronics [8]. In so doing, we will enable a virtual teaching and learning experience that simulates and in many ways enhances the real live experiences. According to actual technology support, we are able to regularly produce eContent and deliver high-quality interactive education programs over network to participants on university level. For example, one of our most innovative and powerful area of eContent application - visualization and simulations improved the complex machine operation in automotive industry (Fig. 1).

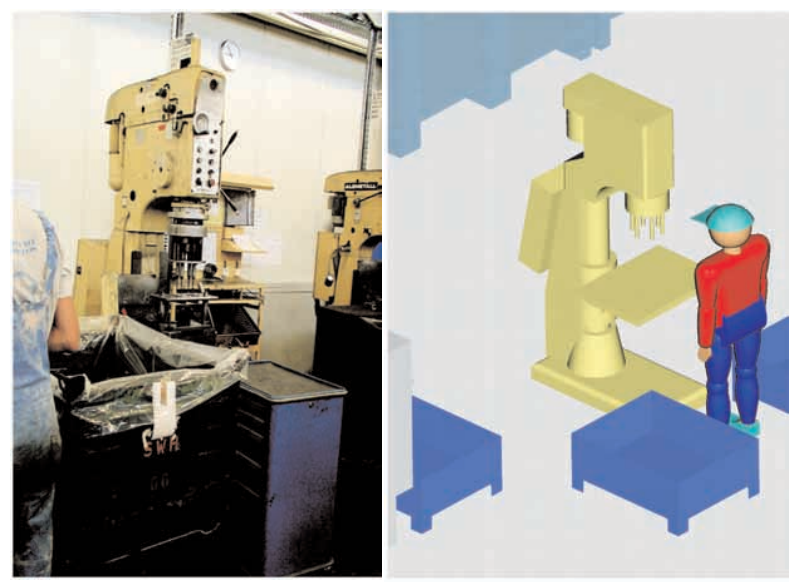

Fig. 1 Imagery (left), movement, virtual modelling and simulation of personel operation (right) in the real environment [5]
The aim of transformation to eMECHATRONICS is to contribute to knowledge economy development by facilitating access and usability of enhanced eContent of mechatronics to all potential users and especially to those from the educational and professional areas. Digital content players in mechatronics are of all sizes, i.e. universities, content creators and owners, packagers and designers, language and customisation players, publishers and distributors, net services companies, rights trading actors, capital market players, experts and market enablers [9]. The main problems encountered in the mechatronics environment are dealing with the integration of several independent well-known techniques from various domains (mechanics, electronics and computing), which, when in synergy, generate easier, more economical, reliable and versatile systems. However their interactions are more difficult to control. Moreover, the mechatronic systems are often critical and their reliability crucial. The educational technology and products are getting more and more complex with immense cost pressure. The mechatronic system requires manifold technology combination of different engineering disciplines, which were traditionally educated separately. It requires new modelling tools and complex systems simulation and standardised software, which facilitate better co-ordination on the development process amongst the various actors. These are classical mechanics and mechanical engineering, material studies, electronics, electrical engineering, drive and control technology, sensor technology, computer science, technical image processing and many more. In engineering education, mechatronics is rapidly expanding, especially in automotive industry, where great successes in the area of robotics, drive technology and automation in vehicle manufacturing have been achieved. In a global and strongly competing industry, mechatronics represents a competitive advantage for the Slovak industry. Universities and productive companies in industries like railway have significant competencies in mechatronic technologies, which already exploit this type of devices (Fig. 2). Market of mechatronic devices in the car industry (sensors, convertors and actuators) already represented nearly 32 billion Euro in 2005 [10]. Mechatronics represented in 2005 nearly $30 \%$ of the cost of a vehicle ( $25 \%$ for electronics). The period 2005-2010 will conduct to a stabilisation of this market. An average growth of $0.4 \%$ over the period will lead to a 32.7 billion Euro market. Mechatronics in the car industry will represent in

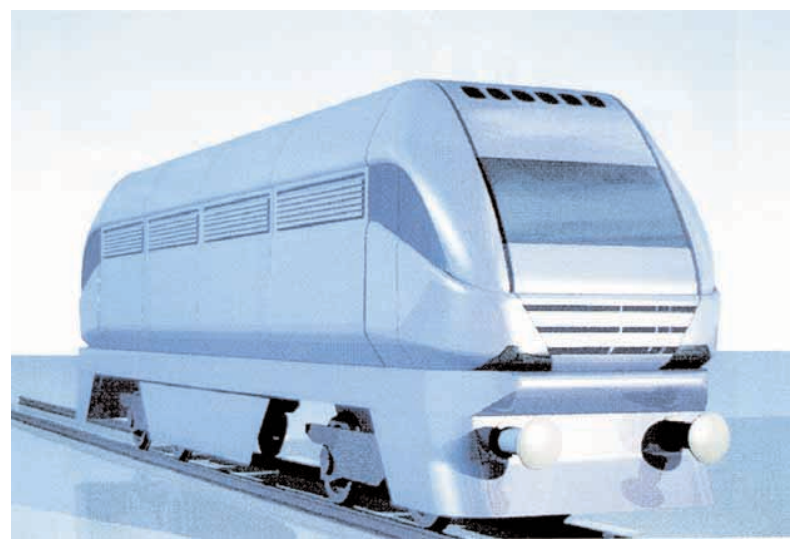

Fig. 2 Virtual art model based on sophisticated technologies for eContent application (designer's model) [12] 
2015 a sales turnover close to 39 billion Euro. Those previsions do not include the progressive penetration of hybrid vehicles. Just like the first developments of electric vehicles marked the arrival of mechatronics, vehicle's hybridisation could be a significant catalyst of mechatronics in the car industry. The European car industry is also facing a very dense lawful and normative context. This context exerts a determining influence on the one hand on the development of electronics in the vehicle and on the other hand on the design methodology and industrial processes of manufacturing.

All the directives contributed at the European level to accelerate the evolution of the technologies deployed. Those new materials, new procedures and new devices are requiring more and more adequacy between basic mechatronical technologies - electronics, mechanics and computing (software, hardware). Moreover, they constitute a barrier at the additional entry on the European market in an increasingly intense competing context. The principal stake of mechatronics is to better take into account more complex interfaces of different natures: technological but also human and organisational. This new context requires closer relations between universities, manufacturers, equipment suppliers and other industries.

\section{Basic Principles of eMechatronics education}

The development of eMECHATRONICS requires educating and training people to a broad panel of technologies. Such professionals will later on assume within their organisation the role of interface between its various development teams. As demonstrated below (Fig. 3, Fig. 4 and Fig. 5), educational activities and eContent materials can come from many different sources, both inside and outside organization (demonstrated shining example of concurrent methodology come out of the R\&D company, university, and railways). Organization's eContent strategies were focused on the diversity of eContent offerings - production, professional training, and university education.

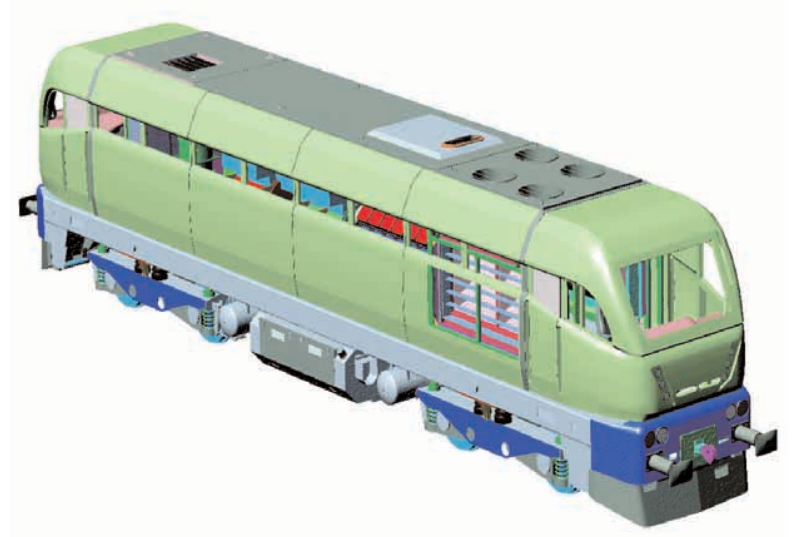

Fig. 3 Virtual parametric model based on sophisticated technologies for eContent application (diesel-electric locomotive in Pro/ENGINEER) [12]

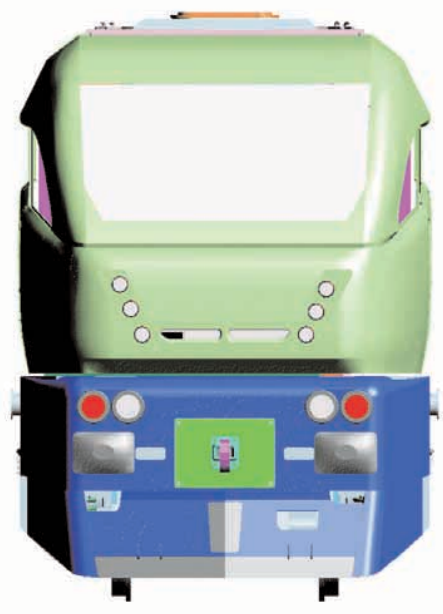

Fig. 4 Standard eContent application (diesel-electric locomotive in Pro/ENGINEER) [12]

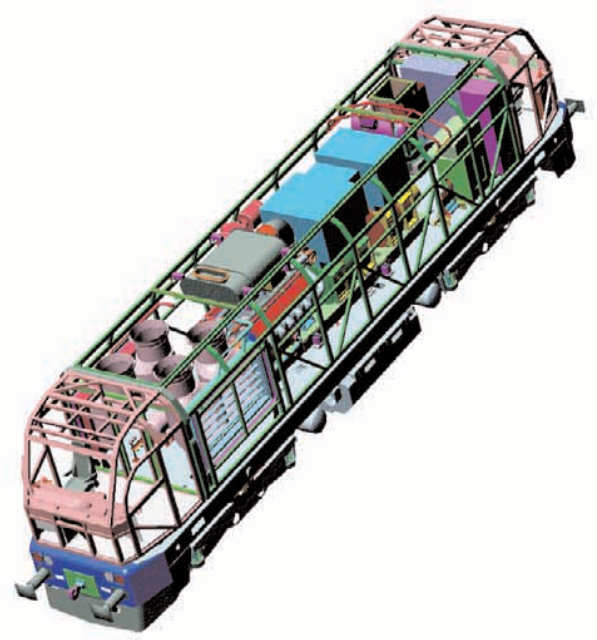

Fig. 5 Virtual parametric model based on modular units for eContent application (diesel-electric locomotive modules in Pro/ENGINEER) [12]

eMECHATRONICS characteristic shows educational needs in a broad spectrum of scientific and technological areas:

- Mechanics,

- Analog and digital electronics,

- Automatic control and algorithmic,

- Networks and associated software (including embedded real-time software),

- Electrotechnics and power electronics, materials and chemistry,

- Design and ergonomics,

- Assembling and packaging,

- Industrial process, etc.

The eContent of mechatronics - documents, case studies and other relevant tools do exist within the universities and faculties, but they truly need to be enhanced and completed for eContent 
strategy so a wider range of possible interactions between the mechatronics various scientific and technological areas be covered [1]. One of the eMECHATRONICS main task will be the selection of analysed documents and its high quality indexing so it fit precisely to the user needs may it be student or professional. The results of its search will be very useful according to its origin, level expertise and knowledge as well as previous use of the eMECHATRONICS service [11]. Concerning multilinguism and cultural adaptation, the achieved solution will provide educational eContent according to the user profile in terms of professional qualification and language. In the first step it is bilingual Slovak/English version of eContent.

\section{Analysis of the demands on eContent strategy}

The results of the eMECHATRONICS based on eContent strategy will be adapted to various educational needs (initial training for students and engineers, on the job training for improving qualification of workers, on demand training and solving problems interface for conception and case study analyse), and level of knowledge, technological backgrounds, languages and cultures [12] The eContent works as a dynamic factor at providing enriched digital content to be found on a really easy and quick way. For young engineers the proposed eMECHATRONICS platform will be an open training area enabling them to learn from senior engineers inputs and arouse their mechatronics awareness using virtual parametric models. The eMECHATRONICS platform will also help to formalise a large variety of eContent: basic training such as an introduction to mechatronics, up to advanced training on specific mechatronics topics or problems. The eMECHATRONICS concept will also help to facilitate cross-fertilisation between disciplines, sites, and companies, in order to find innovative solutions through the implementation of problem solving libraries and tools [1], [8]. In this way, the eMECHATRONICS platform will help to offer the experts, art designers, engineers and technicians' community a large access to mechatronics best practices and know-how. As a result of eContent strategy, eMECHATRONICS should be a major contribution to improve Slovak economy competitiveness as well as components and products overall quality and safety. The eMECHATRONICs users will mostly be in engineering study program students from the network of universities and technical schools as well as professionals from the industry [12]. The OEMs and customers can also be included among the eMECHATRONICS users to identify common strategies and future requests. Regarding students to be targeted, they are several thousands to be taught mechatronics related contents in universities or specialised schools [13].

\section{Description of the objectives and the proposed solution}

The actual tasks of the eMECHATRONICS are willing to form a workgroup, which will build up the structure, method and service for an effective deployment of a bilingual learning tool dedicated to students and professionals concerned with mechatronics. The proposed service will target the real needs of those end users, faced with questions in various scientific and technological fields in which they are not educated and or trained. They may just not have a global view or ignore some scientific and technological interactions, for example between material and physical environment of a technical piece, an electronic chipset and embedded program. The eMECHATRONICS service will propose training elements in relation with a specific question asked through the service. It will then contribute to help understand basic and constituting scientific and technological elements as well as provide some clues to solve problems dealing with issues such as conception, design and production of new integrated elements [14], [15].

eMECHATRONICS will be structured so as to adapt eContent to be provided with the scientific and technological level of qualification of the user, its past search and queries, its knowledge in different domains, learning styles and possible interactions analysed by the system [16], [17]. The constituted database and the user interface will also propose a bilingual tool (in Slovak and in English and possibly with other additional languages) in order to propose a wide understanding (the international industrial companies involved in the mechatronics niche in Slovakia have a huge amount of documents in English). The eContent could be classified according to the mechatronic's principal domains (mechanical, electrical, control and computing) with the help of domain ontology classification (Fig. 6).

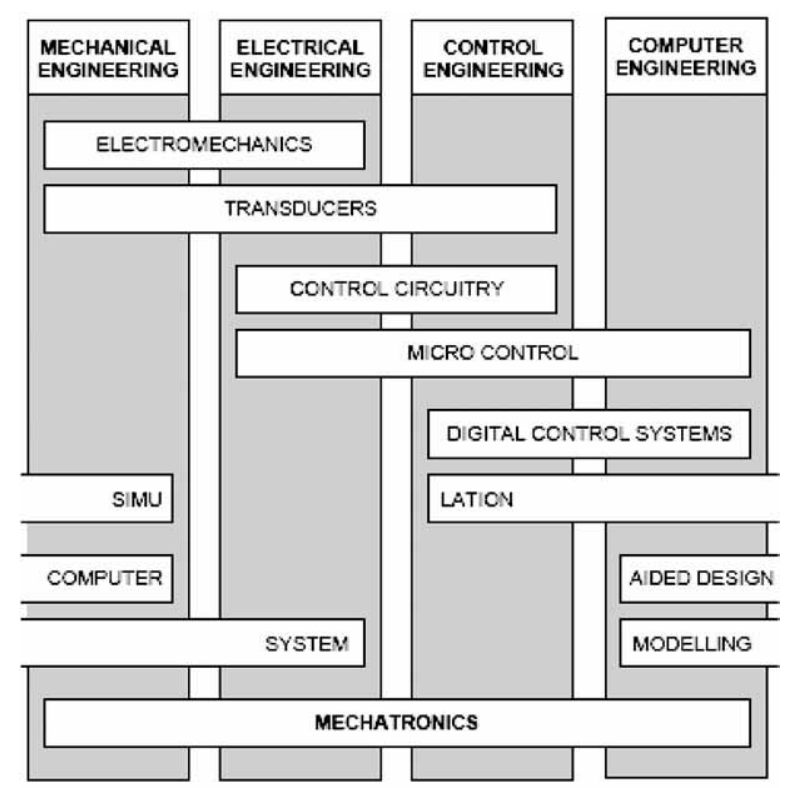

Fig. 6 The eContent classification according to the mechatronic's principal domains [18]

Meta-data on language, region, source type, term classification and text type could also be indicated [18]. To achieve this overall objective, the eMECHATRONICS task will provide:

- knowledge anagement database constituted with existing documents, 
- bilingual glossary about mechatronics based on existing ones to be adapted and completed,

- knowledge management base tool aimed to prepare and assist the enrichment, classification and organisation of existing eDocuments in order to make them more accessible, usable and exploitable,

- training database adapted to the training needs of users constituted with existing training tools improved in terms of quality, efficiency and user-friendly characteristics,

- user-friendly interface based on the analysis of user needs, questions, usual queries, problems and habits of searching as well as on the analysis of possible methods of solving their problems so the results be presented in a manner adapted to train them on the basic knowledge needed to solve the problem they are faced with.

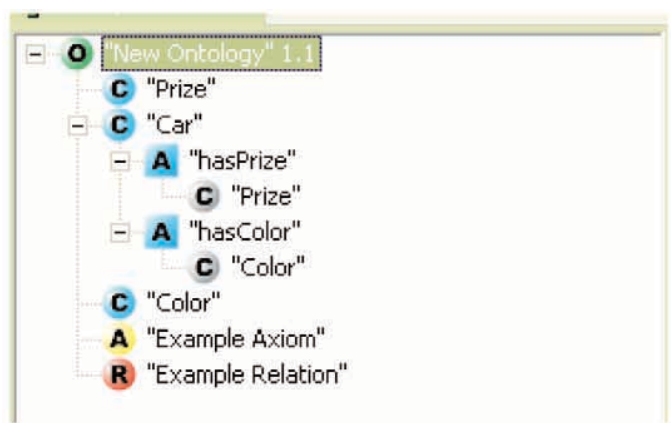

Fig. 7 The integrated ontology editor for editing, browsing and classification for eContent [18]

Therefore, the future work in eContent will carry out the following tasks:

- Search, define and classify existing documents.

- Analyse the user needs and manners of solving problems in order to propose solving problem typologies to be implemented in the user interface,

- Define the user needs in view of constituting the ontologies to improve by means of semantic technology the annotation, enrichment and organisation of existing eContent (Fig.7).

- Construct the tools to search and enrich the existing educating digital documents, the training tool and user-friendly knowledge database interface.

- Constitute the database, implement it within the training tool and test and adapt it after validation by a first end-user group.

- Define various levels of information and their access (private, common or public information), the intellectual rights and quality survey of the product.

- Implement the tool for profiling, filtering and managing the eContent taking also in account the economic return for each content producer.

- Adapt and implement the tools and content of the learning services to user with various profiles and languages.

- Widely deploy and constantly update the eMECHATRONICS services.

- Implement the commercial eMECHATRONICS training services.
At the beginning of the work on the eMECHATRONICS research, development and educational experts, designers, engineers, manufacturing technicians, are daily confronted to:

- choice of design solutions,

- interfaces design and development, test, maintenance, between mechanical parts,

- electronic components and software,

- components manufacturing and maintenance processes and devices.

Through the specific activities, various know-how, return of experience, documents, are available for the benefit of eMECHATRONICS. Concerning complementary existing documents, the searching and indexing system that will be built throughout the transformation to eContent will allow to search on the Internet every other interesting digital content which could enrich the eMECHATRONICS service. So, eContent can be enriched, classified and prepared to be published, brokering services, integrated in the eMECHATRONICS system will support the reusability of any kind of documents.

\section{Bilingual and multicultural aspects of the eContent}

eMECHATRONICS will use the termontography method, which is a multidisciplinary methodology for development of bilingual terminologies. Language-independent domain ontology is constructed and confronted with textual material in different languages. As a result of this confrontation, the framework gradually evolves in an enriched semantic network, reflecting the differences in language, culture and knowledge. The method and tools have been applied in pilot activities in the field of automotive engineering: the compilation of multilingual terminology of an internal combustion engine. This has enabled to constitute a first base of glossary with no more number of words. For the aim of this article, a platform supporting aspects of multilingual knowledge management were used. The final valorisation of existing eContent and organisation of the data will enable to make it accessible for different types of users and applications in different languages. In an initial phase, expert knowledge is used to identify key categories, concepts and conceptual relations by adaptation of the existing multilingual knowledge. In termontography the classification of domain-specific texts uses the domain ontology of the previous phase. In the next phase of transformation to eContent, a multilingual corpus with relevant textual information will be created. Documents will be classified according to the three domains (mechanics, electronics and computing). Meta-data on language, region, source type, term classification and text type will also be indicated. In a third phase, relevant terminology will be extracted from the domain-specific texts. The terms will be connected to categories and concepts of the categorisation framework. Terms, but also definitions, explanations, examples, legal restrictions will be extracted from the documents. The extracted terms, term descriptions and laws will be displayed in the annotation tree. During the term extraction phase, the categorisation framework will enable further refinement. For example, language and culture-specific concepts could be added to the domain ontology. The termontog- 
raphy workbench will also have features to add terminological information to the extracted terms.

\section{Expected results from transformation of teaching and learning}

As the main expected result of the transformation of mechatronics to the eContent strategy, there will be a tool dedicated to training and problem solving in the field of mechatronics usable both by students and engineers who are in everyday contact with mechatronical problems. Transformation to the eMECHATRONICS platform will be based on the following expected results:

- a bilingual indexing tool for documents (studies, research cases, training documents...), and as result,

- a bilingual knowledge base in the field of mechatronics aimed to training of students and professionals,

- a set of methodologies aimed to solve complex problems of integration in mechatronics.

The diversity of eContent formats described in this article indicates that the online learning landscape is highly varied and in a state of flux. Given the many interesting ways to connect people with learning materials and with each other, there is really no reason to continue with the "page-turning" model of e-learning. At the same time, the design of e-learning has become more complex and requires a new set of instructional design skills. Effective teachers know that eContent, used in its broadest sense as an educational task or experience that has some impact on the learner needs to be placed in context and needs to be adapted to the learning abilities, interests, and level of previous knowledge of the learner.

\section{Performance and success indicators}

Within the lifetime of the eContent preparing, constant evaluation will be going on in order to measure the progress achieved and if needed bring corrective measure to ensure the highest level of efficiency, among the activities to be carried out one can note:

- The number and the quality of reachable digital documents contained in the eMECHATRONICS knowledge database.

- Number of entries of thesaurus, meta-data specifications and domain ontologies and content of multilingual glossary will also be surveyed.

- Number and quality of training elements and completion and quality of problem solving tool will also be supervised.

- On the user side, quantity and quality survey will be carried out and will include statistics about number of access to the knowledge database, to the training tools and to the decision-helping tool, including duration of document use or of training time (Fig. 8).

The eMECHATRONICS development is answering to a crucial and actual evolution of the Slovak industry and its achievements will help to make aware both the educational and professional environment of the rapidly changing industrial context and of the necessity to reinforce production organisations' personnel knowledge and know-how on a broad spectrum of scientific and technological areas. The eMECHATRONICS system will in addition complementary to indexing and ontologies identify the documents with their origin (author, owner), value (level of interest, complexity and quality) and status (public, restricted, internal, and private). It will then be easy to complete the system with a brokerage system which will help to evaluate the market value of each document by testing document and knowledge exchange within the participating partners. Interested in the implementation of the eMECHATRONICS system in their professional organisation, the project industrial partners will enable a large dissemination of the results through the network, members, clients, subcontractors and peers. Leaning on a well-adapted and high quality product responding to the user-needs, such service will be easy to replicate to similar challenges. As the system and the methodology developed for eMECHATRONICS is intended to be enlarged or adapted to other domains or fields of interest.
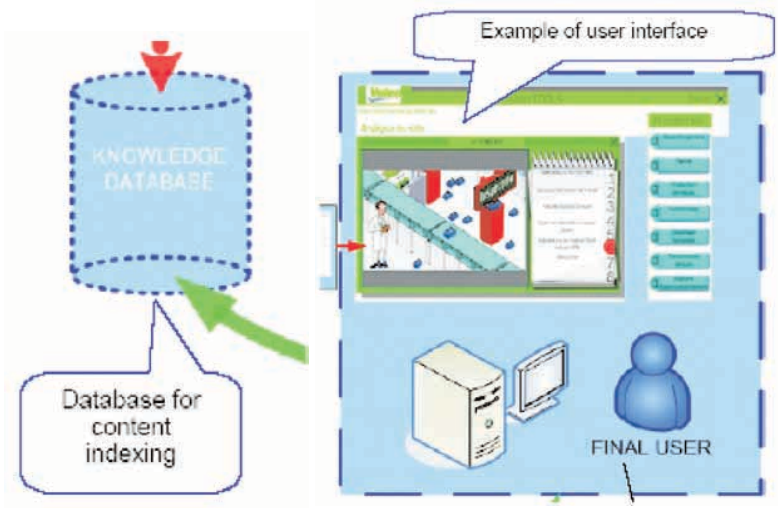

Fig. 8 The user's side of eMECHATRONICS with access to knowledge database, training tools, and decision-helping tools [18]

\section{Analysis of digital documents}

The first work in transformation of mechatronics to eContent will help to define precisely the amount, origin, format, type, language, quality and level of existing digital documents aimed to the use of the eContent strategy, which means documents in the field of mechanics (mathematics, physics), electronics and computer engineering which can be valorised and be used for training purpose. We will also refine our user comprehension by analysing their needs of information and training through case studies with students and employees on their workplace. Qualifying the available digital documents we have to:

- define the criteria of qualifying the available digital documents,

- put on a list of digital documents,

- analyse them by defining their origin (libraries, web, public databases), format (DOC, PDF, graphics, drawings, 3D models, videos, etc.), language, the level of difficulty or speciality, and usability (ready to use or need to be rewritten). 


\section{Description of the future work in eContent strategy}

The investigation of transformation to the strategy eContent will cover the "in-faculty case study" starting from a "problem solving" methodology. Starting from the "mechatronics problems" encountered within the faculty, we have to proceed initially to a clear definition of the problems. This definition starts from a grid of collection, which specifies in particular the noted disfunction, the generated effects, the conditions of use, etc., and then applies a grid in several studies in real situation in the university and the companies. Once the problem identified, this stage of search for causes will be carried out in "expert system". The search for cause and the search for solution of a "mechatronic problem" (complex and relatively new) will constitute the guide for the consultation of databases. The case study will make it possible to check, in which proportion the technical documentary resources meet the mechatronics needs for the companies and will also make it possible to work to improve the access to these resources [18].

\section{Conclusion}

In response to the educational opportunities made available by dramatic technological innovation in the end of 1990s, the eContentplus 4-year programme (2005-2008), proposed by the European Commission in February 2004, will have a budget of _ 149 million to tackle the fragmentation of the European digital content market and improve the accessibility and usability of geographical information, cultural content and educational material. This article has presented far-reaching reason for an effective use of technology in mechatronics education to be better educated and better prepared for the role of eMECHATRONICS in the new Slovak knowledge-based economy. The principal stake of eMECHATRONICS with transformation of knowledge to eContent is to coordinate work and communication between individuals in the chain of value. Students and professionals to be taught eMECHATRONICS will develop multidisciplinary and management skills. Concerned with the aim of this article, we need to calculate with the fact that manufacturers are developing internal training cycles for mechatronics engineers. But at the standard level there is still a great disparity and overall lack of specific training in mechatronics. There are $6-7$ universities in Slovakia proposing courses of mechatronics gathering nearly 400 students per annum (The University in Žilina has been teaching mechatronics since 1990). However, mechatronics educating supports do not exist as such in the form of courses, research, glossaries, and the few materials available are not accessible or adapted to such purpose. In order to face this complexity and versatility regarding mechatronics education contents for both initial and continuous training, there is a need to provide a knowledge base and enriched training contents, which will later help to solve manufacturing problems such as:

- design: appropriate solutions meeting customers' requirements,

- manufacturing: efficient and cost driven manufacturing process,

- interfaces design and development, tests, maintenance, between mechanical parts, electronic components and software,

- components manufacturing and maintenance processes and devices,

- implementation and test: know-how about implementing and testing more and more complex systems,

- operation: product performance, return of experience, reliability, safety issues,

- maintenance: safety, cost,

- breakdown: analyse of cause and prevent integration problems.

Concerning the number of eMECHATRONICS prospective professional end users, it can be evaluated in Europe to a potential of more than 1 million taking into account that only for the automotive industry, there is a potential of $20 \%$ of the 5 million employees in Europe.

\section{Acknowledgement}

This paper was created within support of the Grant Agency of the Ministry of Education of the Slovak Republic VEGA - Scientific Grant Agency of the Slovak Republic for project No. 1/3086/06 "Research of the New Methods of Modelling, Control and Simulation of Mechatronic Systems" and VEGA project No. 1/3123/06 "Research of Commutation Processes in the Power Transistor Structures and Optimisation of their Control at SoftSwitching Mode”.

\section{References}

[1] PAVLÁSEK, P., PAVLÁSKOVÁ, V.: Educational Technology (in Slovak), Textbook for Supplementary Pedagogical Education, EDIS - Editorial Centre of the University of Žilina, 2004, ISBN 80-8070-236-5, p. 83

[2] PAVLÁSEK, P., MEDVECKÝ, Š., CETL, M.: Sophisticated Technologies - Tool for Success in Integrated Design, Local Tradition Global Future, Bratislava, 1997, pp. 55 - 56

[3] CETL, M., PAVLÁSEK, P., MEDVECKÝ, Š., HRČEKOVÁ, A.: Modern Methods in the Product Design (in Slovak), Strojárstvo 3/98, pp. $16-17$

[4] PAVLÁSEK, P.: Sofisticated Technologies in the Design of Products (in Slovak), Strojárstvo 1/97, MEDIA/ST. pp. 24 - 25

[5] MEDVECKÝ, Š., HRČEKOVÁ, A., ŠTRBKA, P., PAVLÁSEK, P.: Design of the Mechatronic Systems with Computer Aid, Proc. of the Science Conference - Using of Unconventional Methods and Materials in Contruction, WPP, Poznañ, October 1996

[6] PAVLÁSEK, P., CETL, M.: The Man and Mechatronics (in Slovak), The Man in the Railway Transport, Proc. of the Seminar ŽELSEM ‘93, Loučeň, 1993, Part II, pp. 229 - 230 
[7] PAVLÁSEK, P., CETL, M.: Configuration of Integrated Mechatronic Systems (in Slovak), Proc. of the International seminar: "Dynamic and solid analysis of the drive systems", Svratka, 1993, pp. 231 - 234

[8] KRÍŽIK, J.: The Light and Shadow (in Slovak), Imaginery in Autodesk 3DS MAX8. Inst. of Art and Science, University of Fine Arts, Bratislava, 2006

[9] PAVLÁSEK, P., KORENČIAK, D., PAVLÁSEK, M.: Conceptual Design of Sophisticated On-board Measuring and Diagnostic System, Proc. of the $5^{\text {th }}$ Intern. Scientific Conf. ELEKTRO 2004, May 25-26, ISBN 80-8070-252-7, pp. $286-291$

[10] The Role of the Fine Art in Perspective of the Acivities of Mechatronics in Automobile Industry in Europe and in France), Mechatronic Study of Renault PSA Cetim/Cabinet Décision - 7/2005

[11] JOCHEMS W., VAN MERRIËNBOER, J., KOPER, R.: Integrated e-Learning: Implications for Pedagogy, Technology and Organization, London, Routledge Falmer, 2004

[12] PAVLÁSEK, P.: Mechatronical Aided Concept (MAC) in Intelligent Transport Vehicles Design. Advances in Electrical and Electronic Engineering, 3-4/2003, ISSN 1336-1376, pp. 38 - 45

[13] PAVLÁSEK, P, GUTTEN, M., KORENČIAK, D.: Measurements and Measuring Systems (in Slovak), EDIS, Univ. of Žilina, 2005, ISBN 80-8070-286-1, pp. 33

[14] PAVLÁSEK, P.: The Main signs of the Mechatronic Equipments (in Slovak), Proc. of the Workshop „Mechatronics”, Supplement of ŽELSEM_93, Loučeñ, October 1993, pp. 7 - 12

[15] PAVLÁSEK, P., KORENČIAK, D., PAVLÁSEK, M. P.: Virtual Instrumentation Based Development of Sophisticated Control System, Proc. of the Inter. Conference Transcom $2005-6^{\text {th }}$ European conference of youth research and science workers in transport and telecommunications, 27.-29. June 2005, Univ. of Žilina, ISBN 80-8070-417-1, pp. 117 - 124

[16] PAVLÁSEK, P., PAVLÁSEK, M. P.: Sophisticated Biometrical System Development for Prompt Eefugee Personal Identification, Proc. of the Intern. Conf. Trends in biomedical engineering, 7.-9. September 2005, Univ. of Žilina, ISBN 80-8070-443-0, pp. 143 - 148

[17] PAVLÁSEK, P., MEDVECKÝ, Š., MAČUŠ, P.: Sophisticated Biomedical Systems: Product Technology, Design and Performance in Dental Medicine, Proc. of the Intern. Conf. Trends in biomedical engineering, 7.-9. September 2005, Univ. of Žilina, ISBN 80-8070443-0, pp. 149 - 154

[18] LAIRE, M., PAVLÁSEK, P., et al.: eMechatronics. Online Web-based Training Solution Devoted to Transfer Emerging Mechatronic Scientific and Technological Knowledge Towards the Educational and Professional Communities, Proposal No. 38217, eContentplus, FIEV, Souresnes, France, 2005. 